\title{
O ensino do direito
}

\author{
A. F Cesarino Júnior \\ Presidente Honorário da Sociedade Interna- \\ cional de Direito do Trabalho e da Segurança \\ Social (Genebra) - Professor Honorário da \\ Universidade Central da Venezuela (Caracas) \\ - Professor da Faculdade de Direito da \\ Universidade Estadual (São Paulo).
}

\section{Introdução}

Professor oficial que somos, há tantos anos, mais por vocação do que por profissão, refletindo sempre sôbre a maneira de melhorar o nosso ensino, conforme já manifestamos em outros trabalhos $\left(^{1}\right)$, julgamos nosso dever insistir no assunto quando ainda se discutem as bases nacionais do ensino brasileiro.

Restringiremos o nosso estudo ao ensino do Direito sôbre o qual reunimos durante vinte anos, numerosas e talvez não inúteis observações.

Referir-se-ão elas preliminarmente à própria existência de Faculdades de Direito, tais como são hoje, ao seu corpo docente, à sua administração, aos títulos que concedem, aos cursos, ao "curriculum", aos métodos de admissão, de ensino e de verificação de aproveitamento dos alunos.

\section{Institutos e não Faculdades}

É nossa opinião que em tôdas as Universidades não se justifica a existência de Faculdades, sendo preferível a adoção do sistema de Institutos dedicados ao ensino e à pesquisa de determinadas especialidades científicas, à sua 
união puramente artificial em estabelecimentos denominados Faculdades.

Com efeito em primeiro lugar, geralmente, não há coordenação alguma no ensino das diversas matérias que constituem o "curriculum" de uma Faculdade. Cada professor leciona sua disciplina como bem entende, sem nenhuma articulação com seus colegas, com absoluta e às vêzes excessiva independência. Logo, para quê a Faculdade?

Por outro lado, há na Universidade um dispêndio inútil de energia, verbas e materiais. Em assembléia universitária tivemos já a oportunidade de lembrar que na Universidade de São Paulo existem numerosas cadeiras de Economia Política na Faculdade de Ciências Econômicas e Administrativas; além dessas há ainda pelo menos mais três: uma na Faculdade de Direito, outra na Faculdade de Filosofia, Ciências e Letras, outra na Escola Politécnica. Logo, outros tantos catedráticos, assistentes, bibliotecas, etc. Porventura são diferentes as "Economias" ensinadas em cada uma delas?

Muito mais acertado seria haver em tôda a Universi dade um único Instituto de Economia, em que esta ciência fôsse estudada sob todos os seus aspectos, começando pelos propedêuticos e básicos até chegar às suas especializadas aplicações. òbviamente para se conceder a uma pessoa o diploma de uma profissão para cujo exercício fôssem necessários conhecimentos econômicos, se lhe deveria exigir o certificado do Instituto de Economia, de que êle ali havia cursado com aproveitamento suficiente as aulas básicas $\mathrm{e}$ as de especialidade a ela correspondente.

É claro que o diploma para o exercício da profissão sòmente seria entregue pela Reitoria da Universidade, conjunto êste de Institutos e não de Faculdades, ao candidato que reunisse a aprovação, nos respectivos Institutos, em tôdas as matérias indispensáveis para o seu exercício. 


\section{Corpo Docente de Carreira}

A atual seleção e organização do corpo docente das Faculdades também é passível de severas críticas.

Efetivamente, no regímen atual muitos professôres se improvisam. É perfeitamente possível atingir a cátedra da mais árdua das disciplinas, sem a menor experiência prévia de seu ensino: basta vencer-lhe o respectivo concurso.

Já fomos ardorosos defensores dos concursos como meio de ingresso, ao magistério superior. Hoje temos sérias restrições a fazer-lhes.

Em primeiro lugar, pelo menos no ensino jurídico, pràticamente a única exigência para ser a êle admitido é a de ser bacharel em Direito. Não se exige, como requisito indispensável, embora sua existência valha para a aprovação, nenhuma experiência anterior profissional, didática ou científica. Teòricamente um bacharel pode inscrever-se em concurso no dia seguinte ao de sua colação de grau. Daí a existência de tantos professôres improvisados, com óbvio prejuízo para o ensino.

Por outro lado, esta convivência mais demorada com êxito não depende exclusivamente do valor científico e didático do candidato, mas exige até mesmo.. condição de resistência física e psíquica. Significa isto que pessoas que tenham aquelas qualidades em grau elevado, mas sejam fìsicamente débeis ou tímidas estão definitivamente impedidas de concorrer ao magistério superior, aberto entretanto a todos os audaciosos, mesmo quando incompetentes.

É verdade que as leis permitem a dispensa de concurso às pessoas de notável saber na especialidade. Mas, não sòmente desconhecemos hipóteses anteriores de sua aplicação, como também pràticamente estão elas revogadas pela Constituição Federal de 1946 que exige sempre o concurso de provas e títulos. 
$O$ ideal seria exigir tal concurso sòmente para a admissão ao posto inicial da carreira, o de assistente. Obrigar-se-iam os assistentes a passar pelos diversos graus, através da demonstração de seu aperfeiçoamento científico pelos trabalhos realizados e publicados: doutor, livredocente e professor adjunto, para só então poder assumir a cátedra, devendo não sòmente durante êste processo, mas igualmente após terminá-lo, apresentar provas da continuidade de seus esforços no sentido não apenas do aprimoramento do seu saber pessoal, como no da realização de pesquisas tendentes a aperfeiçoar a sua especialidade.

\section{Administração dos Institutos}

Há uma verdade tão elementar que a sua compreensão devia ser óbvia e, entretanto, não o é: a de que as escolas são feitas para os alunos e não para os professòres. Êstes são instrumentos de uma atividade cujos beneficiários devem ser a coletividade em geral e, notadamente, os respectivos alunos.

Daí que, da administração dos Institutos devem participar também os alunos. Já têm êles um representante no Conselho Universitário, cuja função é meramente decorativa, porque único. Com efeito, se cada Instituto universitário tem dois representantes tirados do corpo docente, porque os alunos devem ter um único representante? Não é verdade que ainda assim nós, professôres, conservaríamos a maioria de dois a um?

A mesma representação deveriam os alunos ter nos demais Conselhos, como os atuais Conselhos TécnicosAdministrativos e até mesmo nas Congregações, onde não se compreende como não seja ouvida a sua voz. Não temamos pela disciplina: esta deve ser feita na base de compreensão, de entendimento e não vemos como possam entender-se pessoas que não se encontram para discutir os problemas de interêsse mútuo. 


\section{Títulos Universitários}

Já dissemos, mas convém repetí-lo aqui que, devendo o estudo universitário, em nossa opinião, processar-se em Institutos especializados independentes, os diplomas universitários, para o exercício das profissões regulamentadas, deveriam ser concedidos não pelas Faculdades, que não mais existiriam, nem pelos Institutos, que não teriam caráter profissional embora ensinassem também os aspectos práticos da respectiva especialidade, mas pela Reitoria da Universidade, que reuniria todos os Institutos.

\section{Cursos Universitários}

Os cursos universitários ministrados pelos diversos Institutos deveriam ter maior plasticidade, ser mais funcionais. Organizado o ensino superior com base em Institutos científicos e não em Faculdades profissionais, como atualmente, muito fácil seria haver cursos das diversas ciências de diferentes graus, desde as de pura investigação, com caráter de especialização e aperfeiçoamento para post-graduados, até cursos normais ou de graduação e os de mera aplicação dos princípios científicos, destinados a formar práticos. Assim, nos Institutos Jurídicos haveria não apenas cursos para candidatos ao título de advogado, mas, para os portadores dêste título, cursos de alta cultura jurídica, ao mesmo tempo que modestos cursos de notariado, para formar tabeliães, escriviães, escreventes e outros para oficiais de Justiça, para jurados, etc.

\section{Currículo Jurídico}

Em conferência proferida na sessão solene de encerramento da I Semana Mudancista, na Faculdade de Direito, tivemos oportunidade de aludir ao defeito nacional que 
denominamos de "fachadismo", autêntico fenômeno de Potemkin brasileiro: a aparência e não a realidade como preocupação máxima. Daí, no ensino, o exagerado número de matérias e, em cada uma delas, os programas tão extensos quanto inexequíveis. Ao contrário do sábio provérbio "Non multa sed multum", para nós o que importa não é aprender bem poucas matérias, mas sim aprender mal muitas delas.

Tal fato, já de si extraordinàriamente grave, é agravado ainda - se possivel - pela circunstância de serem tôdas essas muitas matérias ensinadas simultâneamente, numa verdadeira visão cinecaleidoscópica, da qual o aluno não poderá guardar senão vagas reminiscências.

Daí a nossa divergência completa do sistema atual e a conseqüente reforma que propomos.

\section{Prioridade às matérias fundamentais}

Uma vez admitida a existência de cursos vários para: práticos, de graduação, post-graduados, de especialização e aperfeiçoamento, para cada uma das disciplinas científicas a serem estudadas, é claro que, tanto o respectivo grau, como o seu número, deverão ficar na dependênciıt da finalidade com que o estudo é empreendido.

No curso jurídico consideraremos tão sòmente, no momento, a finalidade mais importante do ponto de vista utilitário: a de se formarem advogados, juízes, promotores, ou procuradores, objeto do atual curso de bacharelado. Neste, é evidente que deverão ser estudadas, e bem, tão sòmente as matérias indispensáveis para um correto exercício daquelas profissões: "Teoria Geral do Direito" (disciplina que substituiria a atual Introdução à Ciência do Direito), "Direito Civil", "Direito Comercial", "Direito Penal", "Direito Judiciário Civil", “Direito Judiciário Penal", "Direito Econômico" (em lugar de Economia Política), "Direito Tributário" (em lugar de Ciência das Finanças), "Direito Social", "Direito Internacional Públi- 
co", "Direito Internacional Privado" e "Direito Administrativo". Tudo o mais deveria constituir objeto de outros cursos.

\section{Têrmos e não anos letivos}

Atualmente tôdas as matérias são ensinadas simultâneamente, 5 cadeiras no $1 .^{\circ}$ ano, 5 no $2 .^{\circ}, 5$ no $3 .^{\circ}, 6$ no $4 .^{\circ}$, e 5 no $5 .^{\circ}$ da Faculdade de Direito da Universidade de São Paulo, durante o chamado ano letivo, com 3 aulas semanais de 45 minutos para cada uma, exceto a de Introdução à Ciência do Direito, com aulas diárias de igual duração.

$\mathrm{O}$ "ano" letivo começa teòricamente a 1 de março e vai até 15 de junho, no $10^{\circ}$ semestre, seguindo-se as primeiras provas parciais e as férias de julho, recomeçam as aulas a 1 de agôsto, indo até 15 de novembro, vindo a seguir as segundas provas parciais e os exames finais, de segunda época e de admissão, teòricamente até 28 de fevereiro. Conseqüentemente o "ano" letivo dura 3 meses e meio em cada semestre ou seja, 7 meses nos dois, sem contar as interrupções decorrentes de feriados, pontos facultativos, comemorações, greves e faltas dos professôres. Sendo de 12, normalmente o número de aulas mensais (3 por semana), haverá teòricamente 84 aulas de 45 minutos por ano letivo, isto é, 63 horas $\left(\frac{84 \times 45}{60}\right)$ de aula anualmente para cada matéria, o que nos parece realmente muito pouco.

Ora bem, em primeiro lugar, não vemos vantagem alguma no estudo dispersivamente simultâneo de 5 ou 6 matérias, sem nenhuma conexão entre si. Muito ao contrário disto, cremos muito mais útil concentrar a atenção do aluno, durante determinado tempo exclusivamente numa delas. Na Faculdade de Direito da Universidade de São Paulo, as aulas do curso de bacharelado são normalmente de 4 por dia (das 8 às 12 horas, no curso diurno, e das 19 às 23 horas, no noturno). Significa isto a dispo- 
nibilidade mensal de 100 horas (25 dias úteis $\mathrm{x} 4$ horas). Logo, se concentrarmos o estudo de uma só matéria num mês ou melhormente, num mês e uma semana, teremos 124 aulas para cada uma delas no prazo de 7 meses acima referido, isto é, pràticamente o dôbro das atuais (63), nos anos com 5 matérias, e quase o dôbro (100), nós cursos com 6 matérias.

Mais importante que esta verificação, é o fato de que tal estudo concentrado em "têrmos" de um mês ou pouco mais, possibilitaria numerosas e importantes realizações atualmente inexistentes. Assim é que o professor dispondo 4 horas diárias em lugar de 45 minutos, 3 vêzes por semana, poderia abandonar o obsoleto método das prelecões para treinar o aluno na sua matéria, para orientarlhe o estudo pessoal, para encaminhá-lo a proveitosos estágios nos lugares onde se exerçam atividades relacionadas com estudo da matéria, para realizar com êle visitas a ditos lugares, para acompanhar a realização por êle de trabalhos teóricos e práticos em seminários e, principalmente, para seguir-lhe o progresso na aquisição de conhecimentos sôbre a matéria, de maneira a poder realmente aferir-lhe a capacidade adquirida e demonstrada não apenas em duas provas escritas de uma hora de duração, ou numa delas e num exame oral de uns poucos minutos, mas pela efetiva assistência a todos aquêles trabalhos de treinamento efetuados com a sua participação ativa e documentados através dos exercícios realizados seguidamente.

Por outro lado, esta convivência mais demorada com o mesmo professor teria grande valor do ponto de vista das relações humanas, do melhor entendimento entre professor e alunos, do encaminhamento de vocações, de penetração da inteligência do aluno pelo "espírito da disciplina" estudada.

Por outro lado, cumpre notar que, devendo dedicar-se ao trabalho pròpriamente escolar durante apenas um mês ou pouco mais por ano o professor teria muito tempo para 
viajar com fins científicos, realizar intercâmbio com outros professôres, promover e realizar pesquisas demoradas, escrever livros sôbre sua especialidade, etc.

É óbvio que os têrmos seriam escalonados de acôrdo com um critério de dependência das matérias, umas em relação às outras.

Destarte, salvo melhor juízo, proporíamos para o curso jurídico a seguinte distribuição do tempo: $1 .^{\circ}$ ano $-1 .^{\circ}$ têrmo: Teoria Geral do Direito, 1 mês e meio; $2 .^{\circ}$ têrmo: Teoria Geral do Direito Civil, meio mês; $3^{\circ}$ têrmo: Direito de Família, 1 mês; $4 .^{\circ}$ têrmo: Direito das Coisas, 2 meses; $50^{\circ}$ têsmo: Direito das Obrigações, 2 meses e meio; $6 .^{\circ}$ têrmo: Direito das Sucessões, meio mês. - $2 .^{\circ}$ ano - $1 .^{\circ}$ têrmo: Direito Constitucional, 2 meses; $2 .^{\circ}$ têrmo: Direito Comercial (Parte Geral, Comerciante, Sociedades), 2 mêses; $3 .^{\circ}$ têrmo: Direito Comercial (Contratos Mercantis), 2 meses; $4 .^{\circ}$ têrmo: Direito Comercial (Direito Marítimo e Aeronáutico) meio mês; $5 .^{\circ}$ têrmo: Direito Comercial (Falência), meio mês. - $3 .^{\circ}$ ano - $1 .^{\circ}$ têrmo: Direito Econômico, 1 mês; $2 .^{\circ}$ têrmo: Direito Tributário, 1 mês; $3 .^{\circ}$ têrmo: Direito Judiciário Civil (Parte Geral), 2 meses; $40^{\circ}$ têrmo: Direito Judiciário Civil (Processo Ordinário), 2 meses; $5 .^{\circ}$ têrmo: Direito Judiciário Civil (Processos Especial e Acessórios), 1 mês. - $4 .^{\circ}$ ano - $1 .^{\circ}$ têrmo: Direito Internacional Público, 1 mês; $20^{\circ}$ têrmo: Direito Internacional Privado, 1 mês e meio; $3 .^{\circ}$ têrmo: Direito Penal (Parte Geral), 1 mês e meio; $4 .^{\circ}$ têrmo: Direito Penal (Parte Especial), 1 mês e meio; $5 .^{\circ}$ têrmo: Direito Penitenciário, meio mês; $6 .^{\circ}$ têrmo: Medicina Legal, 1 mês. $-5 .^{\circ}$ ano $-1 .^{\circ}$ têrmo: Direito Judiciário Penal, 2 meses; $2{ }^{\circ}$ têrmo: Direito Administrativo, 2 meses e meio; $3 .^{\circ}$ têrmo: Direito Social (Parte Geral), $1 / 4$ de mês; $4 .^{\circ}$ têrmo: Direito Corporativo, $1 / 4$ de mês; $50^{\circ}$ têrmo: Direito do Trabalho, 1 mês e meio; $6 .^{\circ}$ têrmo: Segurança Social, meio mês. 
As atuais matérias do Curso de Bacharelado não constantes da lista acima (Direito Romano, Teoria do Estado, e Filosofia do Direito) seriam estudadas em cursos de postgraduação ou de doutoramento. Como já se viu, propusemos a substituição da Introdução à Ciência do Direito, pela Teoria Geral do Direito, da Economia Política pelo Direito Econômico, da Ciência das Finanças pejo Direito Tributário.

\section{Métodos de admissão}

É muito brusca a passagem do curso colegial para o universitário, dada a diferença de grau e de método entre os dois níveis de ensino. Por outro lado há também necessidade de um esfôrço no sentido de suprir, na medida do possível, as eventuais deficiências do curso secundário.

Estas vantagens se encontram, a nosso ver, na criação de um ano intermediário, pré-universitário, no qual se estudariam durante um período, digamos de 8 meses, as matérias propedêuticas para o curso a que o aluno se destina. Para nós deveriam ser estas as matérias dêsse curso pré-jurídico, cuja aprovação permitiria, na proporção das notas obtidas em relação ao número de vagas, a matrícula na Faculdade de Direito: $1^{0}$ têrmo: Organização do Trabalho Intelectual, 1 mês; $20^{\circ}$ têrmo: Estatística, meio mês; $3 .^{\circ}$ iêrmo: Sociologia, 1 mês $-4 .^{\circ}$ têrmo: Política, 1 mês; $5 .^{\circ}$ têrmo: Psicologia, 1 mês; $6 .^{\circ}$ têrmo: Lógica, 1 mês; $7 .^{\circ}$ têrmo: Contabilidade, meio mês; $8 .^{\circ}$ têrmo: Economia, 1 mês; $90^{\circ}$ têrmo: Redação, 1 mês.

Parece-nos evidente que o conhecimento destas disciplinas é muito mais importante para o estudo, tanto científico como prático do Direito, do que o das matérias atualmente exigidas: Português, Latim, Francês ou Inglês. Com efeito, salvo o vernáculo, o conhecimento de uma língua estrangeira, embora útil, não é indispensável porisso que, além de já termos bem desenvolvida a literatura jurí- 
dica nacional e lusitana, as principais obras estrangeiras já estão traduzidas, seja para o português, seja para o espanhol, êste último compreensível sem grandes estudos.

Quanto ao latim, sempre consideramos obsoleto o estudo do mesmo no curso secundário, que o inclui no seu currículo, por mero fachadismo. Estude-o quem quiser dedicar-se, em curso post-graduado, ao Direito Romano. Para os demais é pràticamente inútil.

\section{Métodos de ensino}

Consideramos inteiramente superados os atuais métodos de ensino jurídico, consistente quase em tôda a parte, exclusivamente nas preleções magistrais, anotadas pelos alunos para formarem as apostilas ou "sebentas", cuja decoração ou cópia, conforme a maior ou menor exigência dos professôres, garante a aprovação numa das numerosas oportunidades concedidas aos alunos para galgarem a série seguinte.

Com ef eito, sendo o curso jurídico normal, o atual bacharelado, um curso profissional, embora de nível superior, nêle se deve fazer o treinamento dos futuros juristas para as profissões a que se destinam: juízes, promotores, advogados, procuradores, etc. Ora bem, é claro que tal formação exige o conhecimento técnico dos princípios dos diversos ramos do Direjto. Mas, é evidente também que, em se tratando de um curso de formação e não de aperfeiçoamento das aptidões jurídicas dos alunos, tem êle caráter elementar. Ora, assim sendo, parece-nos muito mais consentâneo que os alunos aprendam os dados fundamentais das diversas disciplinas, a sua nomenclatura técnica, a sua aplicação à realidade ambiente, através do manejo dêsses dados e dessa nomenclatura na solução de questões teóricas e na resolução de casos práticos. Sobretudo é importante que, através de estágios nas instituições respectivas, os alunos vejam como funcionam os diversos institutos juridicos, não sòmente nas suas manifestações 
normais - atos juridicos, euremática forense, jurisprudência administrativa - mas também nas anormais jurisprudência judiciária — de tal maneira que não se estudem apenas a anatomia do Direito - Legislação - e a sua patologia - jurisprudência judiciária - mas também a sua fisiologia - advocacia preventiva, atividades tabelioas, e administrativas.

Em nossa opinião a lei deveria estabelecer a obrigatoriedade do exercício, pelo menos em tempo parcial, por exemplo no periodo da tarde, de certas funções forenses pelos estudantes de Direito: assim, os primeiranistas seriam oficiais de Justiça; os alunos do segundo ano, escreventes de cartórios cíveis, os de terceiro ano, escreventes de cartórios criminais, os de quarto ano, secretários das Juntas de Conciliação e Julgamento, e os bacharelandos, já solicitadores-acadêmicos, fariam um ano de estágio junto às varas e curadorias ou promotorias cíveis, de família e sucessão, criminais e trabalhistas.

Todos os estágios seriam orientados pelo professor, precedidos do exame de minuciosos questionários e seguidos da apresentação de não menos pormenorizados relatórios sôbre as observações durante êles realizadas.

O estudo teórico seria feito da seguinte maneira: depois de ligeira explanação do professor, tendente apenas a situar o problema a ser estudado e a indicar-lhe as fontes jurídicas e a bibliografia acessível aos alunos, deveriam todos êstes preparar-se para expô-lo brevemente e discutílo com os colegas, seguindo-se a crítica do professor. Do resultado da discussão seriam igualmente elaborados relatórios.

As điscussões não seriam restritas apenas à solução de problemas teóricos, mas também se dariam para a resolução de casos práticos e para a crítica de decisões da jurisprudência.

Aspecto que nos parece de grande relevância é o de manter os alunos a par de todos os fatos do momento de interêsse para a disciplina estudada: daí a organização de 
hemerotecas, com recortes devidamente analisados de noticias referentes aos fatos relacionados com os assuntos examinados em aula. Igualmente importantes são os exames completos de processos findos, analisando-os criticamente quanto ao fundo (questões resolvidas) e quanto à forma (atos processuais), e a exata aplicação das normas legais.

A redacão de peças jurídicas, tanto judiciais, como extrajudiciais e a sua sujeição à crítica dos professôres ou de seus assistentes, também nos parece de grande alcance didático.

Por último, lembrariamos a conveniência de serem ouvidas pelos alunos palestras de expoentes da disciplina estudada, seja em seus aspectos técnicos, seja nas suas aplicações práticas.

\section{Métodos de verificação do aproveitamento}

Igualmente condenáveis são os atuais métodos de verificação do aproveitamento dos alunos. Com efeito, êles se reduzem à criticada reprodução decorativa ou cópia das apostilas ou "sebentas" Tal sistema permite a aprovação e, conseqüentemente a diplomação de pessoas sem nenhum preparo real, apenas porque nas vésperas ou antevéspera do exame, delas fizeram uma apressada leitura.

A nosso ver seriam muito mais expressivas do grau de aproveitamento dos alunos as notas graduadas de zero a 10, dadas pelo professor e seus assistentes nos relatórios a que acima nos referimos, isto é, resumos das discussões teóricas, das soluções dos casos práticos e dos resultados de estágios realizados. O exame deveria ser realizado através da resposta a "tests" versando sôbre tôda a matéria estudada. Seriam considerados aprovados os alunos que tivessem $4 / 5$ de freqüência a tôdas as aulas dadas e $75 \%$ de acêrto nas respostas aos "tests" e nota igual nu superior a 6 nos referidos relatórios. 


\section{Conclusão}

O que acima foi dito, representa apenas um punhado de sugestões apresentadas com a intenção de colaborar para o melhoramento do nosso-ensino jurídico. Naturalmente elas visam despertar para os problemas ventilados a atenção das pessoas competentes no assunto, a fim de que, reunidos todos os esfôrços se possa, em breve tempo, atingir aquêle ideal de aperfeiçoamento.

(1) Cf. - Sôbre o ensino do Direito, in "Revista da Faculdade de Direito da Bahia", vol. XI, de 1952, pg. 71; A Faculdade de Direito de São Paulo deve ganhar em profundidade o que perdeu em extensão, na "Folha da Manhã", de São Paulo, de 7 de abril de 1949; O Ensino do Direito, Tese apresentada ao I Congresso Nacional de Ensino Jurídico, in "Revista da Faculdade de Direito de São Paulo", vol. XLIX, de 1954, pg. 180; e A função social do jurista e a reforma do ensino do Direito, in "Revista da Faculdade de São Paulo", vol. L, de 1955, pg. 234. 